\title{
Measuring Intensity - Describing and Analysing the "Urban Buzz"**
}

Tim Stonor*

\section{Density or Intensity?}

There is much debate about how to measure density - dwellings per hectare, bedrooms per hectare or people per hectare; including or excluding major highways, parks and open spaces; the permanent population only or the transient one too?

While this gives urban planners something to disagree about it risks missing the point: great urban places are not created by density; they are created by intensity.

And the difference matters. When people describe the buzz of a marketplace (figure 1.) they do not say, "Wow - it was so dense!". They are much more likely to say how intense it was. Density is a word used by planners. Intensity is a word that real people use, and perhaps because it describes the outcomes that people experience rather than the inputs that have gone in to creating them. It is the outcomes that are ultimately more important.
*Managing Director of Space Syntax, Visiting Professor at UCL.ORCID

E-mail: t.stonor@spacesyntax.com

${ }^{* *}$ Morphology, Plenary section (invited speech, unpublished). 
Figure 1. Trafalgar Square Central Steps, London, UK, redesigned following careful observation of human behaviour and computer modelling of future pedestrian movement flows that prioritise people over the movement of vehicles. (Space Syntax Limited (C) 2019) (Stonor, 2019)

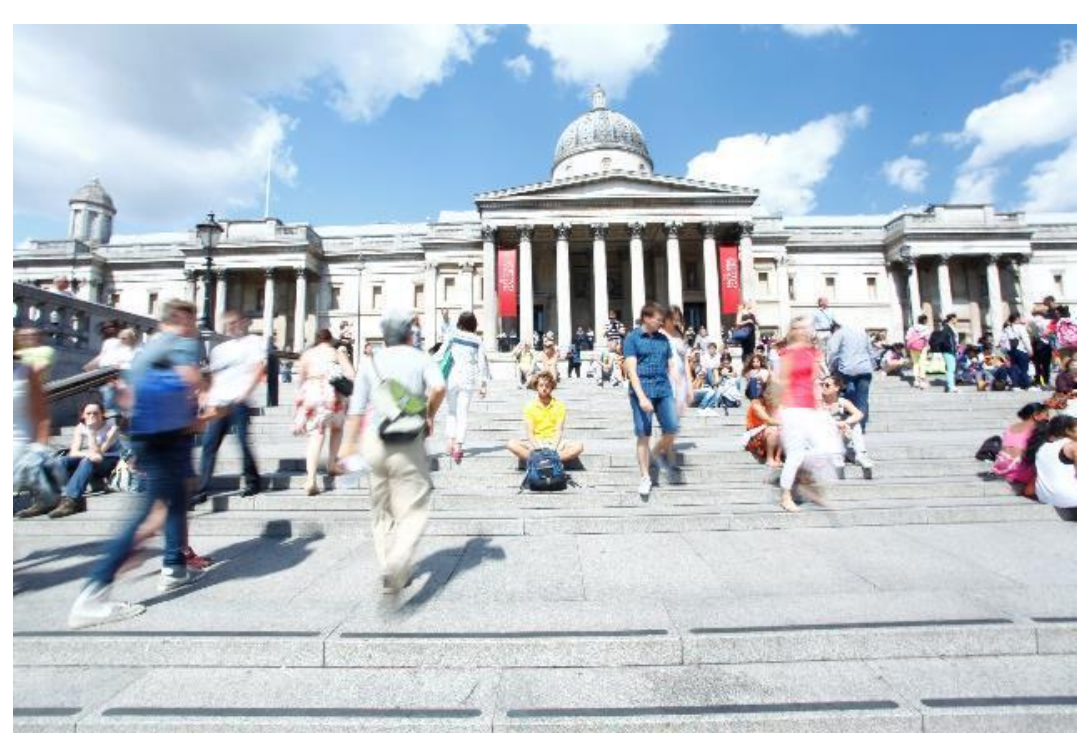

But planning professionals like density. Even though density fails to capture the essence of what it feels like to be somewhere, the term appeals to professional instincts. It describes the raw ingredients that planners have to handle and, once you choose which version of the formula you are going to use, density is easy to measure. It involves a simple calculation of straightforward urban quantities such as the number of people, the number of houses or the number of bedrooms, all divided by the geographic area over which those ingredients occur. Easy.

In contrast, intensity seems more difficult to pin down, not least because it appears to have a subjectively emotional dimension; it speaks of feelings, of responses, of stimuli, and this raises problems about how it can be effectively measured. But intensity is also a response to context, to place and above all to people - and here we can find clues to its measurement.

\section{Observing Intensity}

So what are the factors that people are responding to when they instinctively feel the intensity of a great place? For a start, they can not be calculating a planner's measure of urban density because, even if they were so minded, they could not possibly know about populations and geographic areas when they are walking along a street or sitting at a café table on a public space.

What people can respond to though is what is happening around them in the public realm: they can see how many other people there are, and they can see what these people are up to. In other words, intensity is obvious, immediate and instinctively calculable to the person in the street: not only the mobile population of walkers, drivers and cyclists but also the immobile population of sitters, leaners and pausers. Intensity has a static as well as a kinetic dimension. Indeed the stationary people are the essential 
ingredient of intensity. They are the people who have chosen to be there, to add to the place through their semi-permanence and not simply to pass through on the way to somewhere else. Intensity is not therefore about the population density of an area but the population that is participating in the public realm of an area. And this should be obvious. And everyday. But any attempt to emphasise the benefits of static participation runs counter to the mindset of the traffic engineer and counter to the still-persuasive, kinetic legacy of Le Corbusier, who described "grinding gears and burning gasoline" as the pleasurable objectives of the Plan Voisin.

Nevertheless, intense places are sticky places and especially so when people are not only co-present in space but when they are also interacting: talking to each other, sharing thoughts, ideas, opinions. This is the essence of intensity; there is an exchange - a transaction - be it economic, social, cultural, intellectual, factual or simply facile. It is the daily public life of every thriving village, town and city. It is so apparently unremarkable as to go unnoticed, unobserved and unmeasured. Until it is not there. And that is when you feel it most clearly.

A number of years ago my colleagues at Space Syntax were working on a sample of towns across the UK, some historic and some new. The towns had similar residential populations and similar retail floorspace provisions across similar geographical areas; in other words, similar densities. But what the team had also done was to count the numbers of people using the centres of each town: how many were walking and sitting in public space. They had counted over several days, from morning until evening. What they found was that the historic towns consistently had many more people using their centres than the new ones - and they knew from other evidence that the historic towns had stronger economic performances. Here then were places with similar urban densities but different intensities of human activity.

What seemed to explain the differences between historic and new towns were first, the spatial layout and second, the street design of each place. The historic towns were laid out around radial streets that were designed to carry cars as well as vehicles and which met at the centre of the town in a public space. Behind these radial streets were more or less continuously connected grids of residential streets, interrupted by the occasional large open space. Both cars and pedestrians could use the residential streets, while the open spaces were generally for pedestrians only. There was some limited pedestrianisation in the very centre of each town. 
In contrast, the new towns often had separate street networks for vehicles and pedestrians, no high street or central public space and usually one or two enclosed shopping malls. Their central areas were typically pedestrianised and spatially separated from the surrounding residential areas by a vehicle-only ring road; these residential areas were separated from each other by large swathes of open space.

To summarise, the key differences were first in the intensity of the human experience and second in the design of the street network. Intensity, it seems, is facilitated by an alignment of physical and spatial factors: having the movement-sensitive land uses on sufficiently well-connected streets that are, in the main, shared by vehicles and pedestrians.

\section{Measuring Intensity}

Importantly, both the amount of human activity and the degree of street connectivity are measurable commodities - if you know how. This is the professional specialism of my practice, Space Syntax, and it has two key parts: one part that takes place in the studio, using purpose-designed software that measures the amount of connectivity in street grids (figure 2.), and the other part that happens on site using some form of counting device. This device may be a camera strapped to a lamp post or, in recent years, a drone flight. Or it may simply be a set of human eyes, a pencil and a notepad.

Figure 2. Spatial Accessibility Model of Thamesmead, UK, showing the hierarchy of street connections from most accessible in red, then orange through yellow and green to least accessible in blue. Practice demonstrates that spatial accessibility is a robust proxy for movement, land use vitality, land value and other key urban performance indicators. (Space Syntax Limited (C 2019)

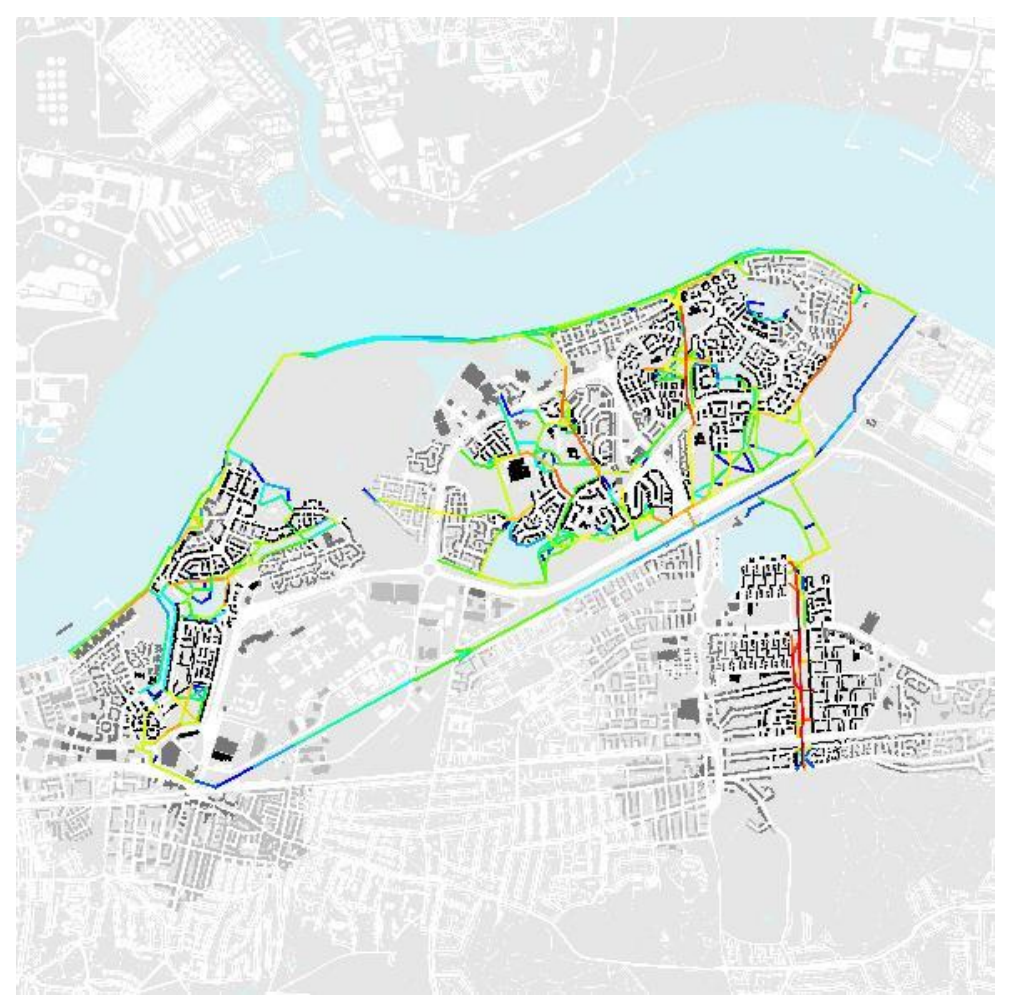


Onto these 'foundational' datasets are added other information, which might be about air quality, land value, crime rates or health outcomes. Statistical software is employed to explore relations between the datasets: how is health or wealth or educational achievement related to spatial connectivity or isolation? The product of this process is an Integrated Urban Model: a quantitative record of urban form and urban performance (figure 3.). A Geographical Information System is used to hold the datasets in one place and a basic form of artificial intelligence is run to explore the links between the data.

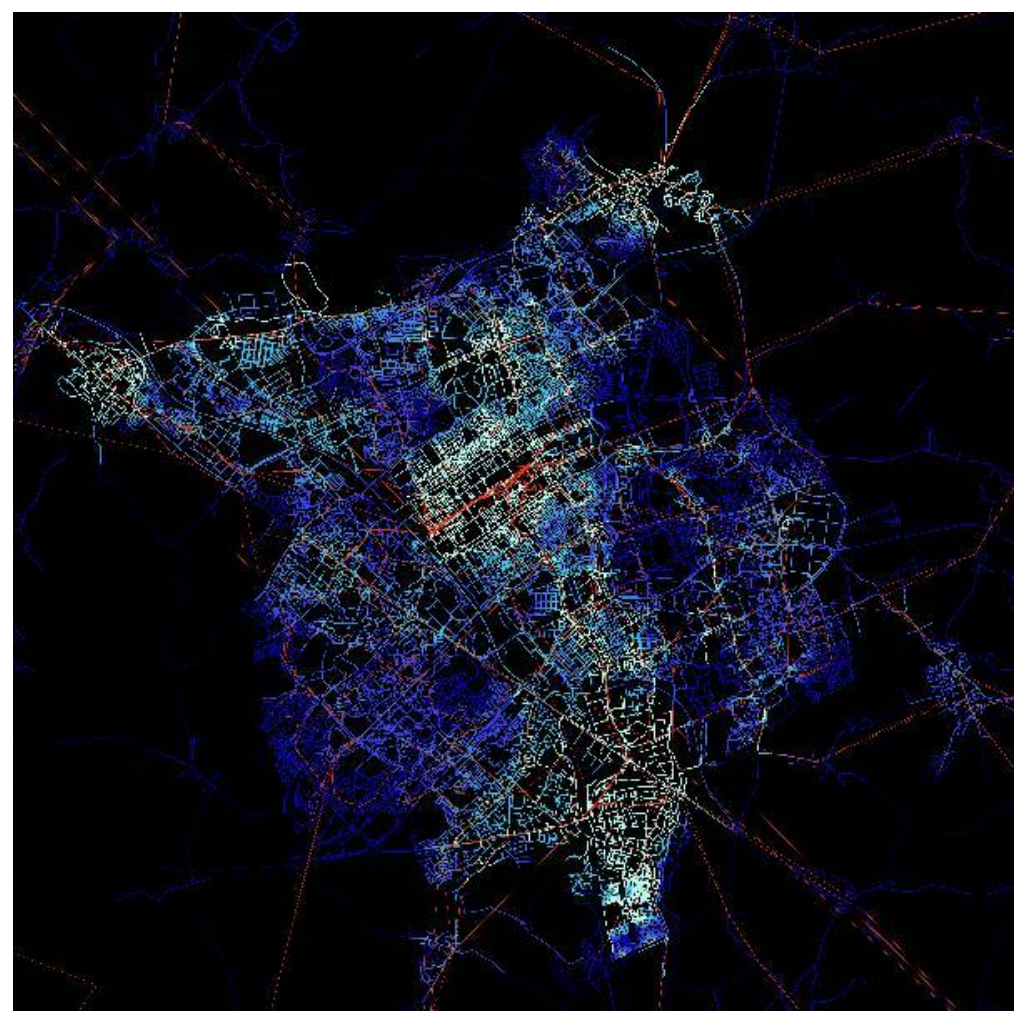

Figure 3. Integrated Urban Model of Milton Keynes, UK, combining data on spatial layout, land use and public transport accessibility to address cardependence and social isolation. (Space Syntax Limited (C) 2019) (Parham, 2017)

However it is possible to create a primitive version of a data platform using only PowerPoint and Excel. After all, Space Syntax began its work before the Macintosh, before colour screens, before the internet, before CAD, before GIS and long before BIM. Its observations of pedestrian movements around Trafalgar Square were done with pen and paper, the results coded manually into a simple drawing programme.

What matters today is what mattered then: to bring data to life using maps and colours rather than spreadsheets and charts (figure 4.). To make it accessible to the audiences that will be making judgments about the future of places: investors, planning officers, politicians and local communities. Measures of intensity therefore need to speak to multiple audiences and not least to the design community, into whose creative hands is entrusted the responsibility for shaping the aspirations of stakeholders. An 
Integrated Urban Model must be nimble, capable of responding again and again to the short and intensive programme of a rapid design process. Beware the Smart City "Control Room" stuffed with technicians; eintegratedmbrace instead a portable platform that can respond to the timescale of a creative whim.

Figure 4. Land use catchment analysis of the Royal Borough of Greenwich, UK. The degree of access to different amenities and their mix defines the character of an area by creating a more walkable and vibrant urban context, 2019. (Space Syntax Limited (C) 2019) (Hillier \& Stonor, 2017)

\section{chat can respond to the timescale of a creative whim.}


should be broken up into manageable parcels. Since we want pedestrians then we should pedestrianise.

We end up with an urbanism of averages and a morphology of enclaves through an approach that is much too simplistic to ever create great place. It is not born of science and it does not reflect human experience: people know instinctively that you can turn off the busiest street in the city and immediately find yourself on a lane that is one of the quietest; that the intensity of the urban experience can transform itself in seconds. This is one of the great joys of exploring great cities: they are not pervasively busy; they are intensely quiet as well. They have a foreground grid of busy streets and a background grid of quiet ones. If we can systematically measure urban intensity then we will understand how towns and cities work in ways that will transform practice. And by transforming practice we will transform place (figure 5.).

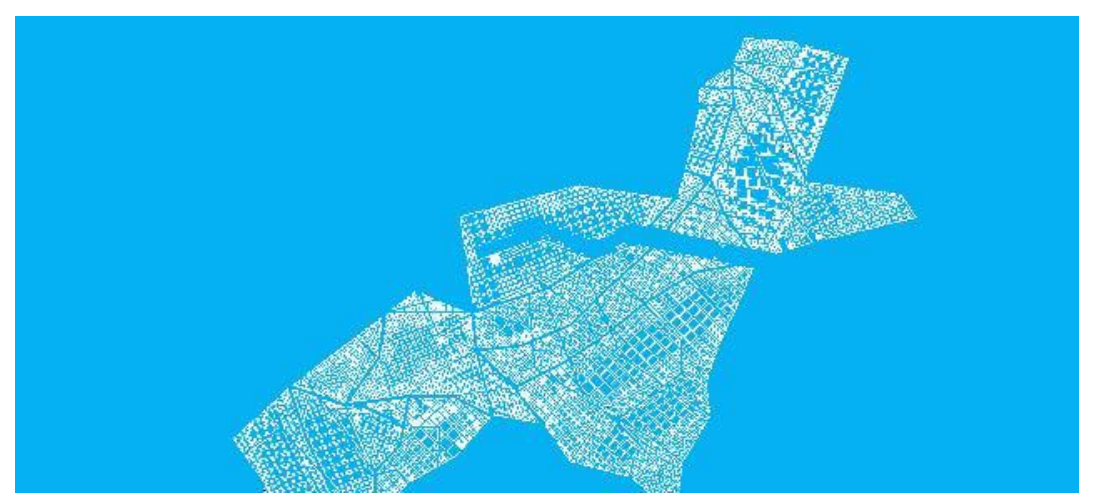

\section{The Future for Intensity}

The professions will be unwise to avoid the opportunities presented by technology. Both the technologies of data capture, visualisation and analysis as well as the technologies that are affecting human behaviours: broadband, social media, augmented reality (AR) and artificial intelligence (AI). Human activity is becoming ever more intense and this gives us another reason to systematically measure urban intensity. People are walking more slowly, ensconced in virtual worlds at the same time as participating in physical space; seeing their surroundings augmented with pop-up information. The trend will continue as AR on our smartphones becomes AR on our spectacles. As well as talking to each other we will be talking to objects on display in shops, to screens in buildings and on streets, and to ourselves our digital twin may appear as an avatar walking alongside us in our peripheral vision or in front of us when trying on clothes for us. This intensity of communication can already be seen in early adopting countries, especially China, and it may seem strange at first. But there was a time, not long ago, when it seemed strangely
Figure 5. Nur-Sultan Masterplan, Kazakhstan, in which an urban block structure creates a network of busy 'foreground' and quiet 'background' streets. (Space Syntax Limited (C) 2019) (URL-1) 
ostentatious to put down a mobile phone on a table in a public place.

The brain has a finite processing capacity and so what goes into handling increased visual information will have to be taken away from the control of bodily function. People may therefore adapt to the amplified intensity of visual stimuli by moving ever more slowly. We will need more space for these intense activities and the obvious place is the street, where we will need more space for people. Road space will have to narrow and footways will have to widen. We will need more places to sit and lean - to be sticky.

And this presents a choice for designers: continue to disagree about the best way to measure density or embrace intensity and anticipate the radical transformation of place (figure 6.).

Figure 6. Nur-Sultan Masterplan, Kazakhstan, created by Space Syntax through a place-based and datadriven design process. (Space Syntax Limited (C) 2019) (URL-1)

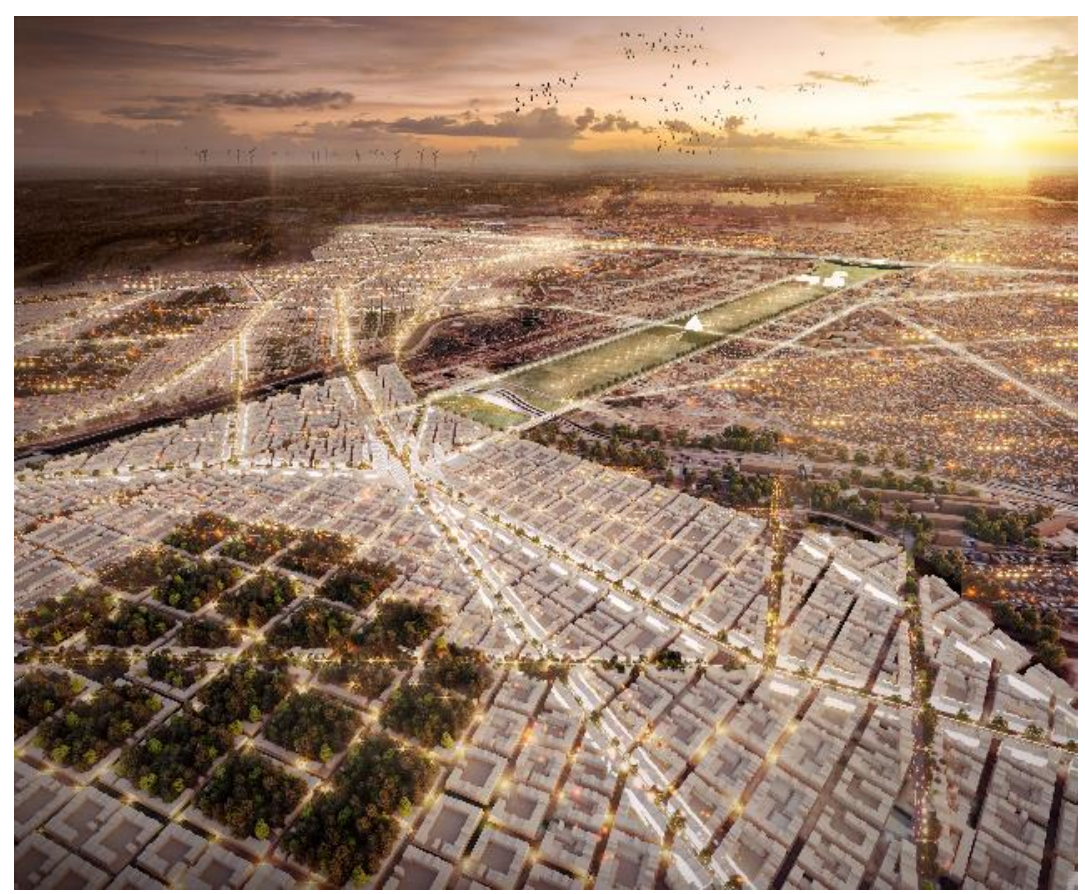

\section{REFERENCES}

Hillier, B., \& Stonor, T. (2017). Kevin Lynch Memorial Lecture. Retrieved from https://timstonor.wordpress.com/

Parham, E. (2017). Milton Keynes Housing and Transport Strategy. Retrieved from https://spacesyntax.com/project/miltonkeynes-housing-and-transport-strategy-2/

Stonor, T. (2019). Beyond Placemaking: 7 Dimensions of "Place Performance". Retrieved from https://timstonor.wordpr ess.com/

URL-1. Master Plans. Retrieved from https://spacesyntax.com/ 


\section{Resume}

Tim Stonor is an architect and urban planner who has devoted his career to the analysis and design of human behaviour patterns: the ways in which people move, interact and transact in buildings and urban places. He is an internationally recognised expert in the design of spatial layouts and, in particular, the role of space in the generation of social, economic and environmental value.

Tim is the Managing Director of Space Syntax, an urban planning and design company created at University College London in 1989 to develop and apply predictive design technologies. He is a Director of The Academy of Urbanism, a Visiting Professor at The Bartlett School of Architecture, University College London, a Harvard Loeb Fellow and Deputy Chair of the UK Design Council. 